\title{
Parietex $^{\mathrm{TM}}$ Composite mesh versus DynaMesh $^{\circledR}$-IPOM for laparoscopic incisional and ventral hernia repair: a retrospective cohort study
}

\author{
A Tandon ${ }^{1}$, K Shahzad ${ }^{1}$, S Pathak ${ }^{2}$, CM Oommen ${ }^{5}$, QM Nunes ${ }^{1}$, N Smart $^{2}$ \\ ${ }^{1}$ Department of Surgery, Aintree University Hospital, Liverpool, UK \\ ${ }^{2}$ Exeter Surgical Health Services Research Unit (HESRU), Royal Devon and Exeter NHS Foundation \\ Trust, Exeter, UK \\ ${ }^{3}$ Rotherham General Hospital, Rotherham, UK \\ ABSTRACT \\ INTRODUCTION Laparoscopic incisional and ventral hernia repair (LIVHR) is widely accepted and safe but the type of mesh \\ used is still debated. We retrospectively compared postoperative outcomes with two different meshes commonly used in LIVHR. \\ METHODS This is a retrospective study of patients who underwent incisional hernia repair between January 2008 and Decem- \\ ber 2010. Two meshes were used: Parietex ${ }^{\text {TM }}$ Composite (Covidien, New Haven, CT, USA) and the DynaMesh ${ }^{\circledR}$-IPOM (FEG Tex- \\ tiltechnik $\mathrm{mbH}$, Aachen, Germany). The two groups were compared with respect to recurrence rates, incidence of seroma and \\ intestinal obstruction. \\ RESULTS Among the 88 patients who underwent LIVHR, 75 patients (85.2\%) presented with primary incisional hernia, 10 \\ (11.4\%) presented with a first recurrence and 3 (3.4\%) presented with a second recurrence. Median follow-up was 53.6 \\ months (range $40-61$ months). $12.9 \%$ of patients had recurrence in the Parietex ${ }^{\mathrm{TM}}$ Composite mesh group ( $\left.n=62\right)$ in compari- \\ son to $3.8 \%$ in the DynaMesh ${ }^{\circledR}$-IPOM mesh group $(n=26 ; P=0.20)$. DynaMesh ${ }^{\circledR}$-IPOM was associated with a significantly higher \\ incidence of intestinal obstruction secondary to adhesions $(11.5 \% \mathrm{vs} .0 \%, P=0.006)$ and lower incidence of seroma and hae- \\ matoma formation compared to Parietex ${ }^{\mathrm{TM}}$ composite mesh group ( $0 \% \mathrm{vs} .6 .4 \%$ of patients; $P=0.185$ ). \\ CONCLUSIONS LIVHR is a safe and feasible technique. Dynamesh ${ }^{\circledR}-$ IPOM is associated with a significantly higher incidence of \\ adhesion related bowel obstruction, albeit with a lower incidence of recurrence, seroma and haematoma formation compared \\ with Parietex ${ }^{\mathrm{TM}}$ Composite mesh. However, there is a need for further well-designed, multicentre randomised controlled studies \\ to investigate the use of these meshes.
}

\section{KEYWORDS}

Incisional hernia - Laparoscopic mesh repair

Accepted 7 August 2016

CORRESPONDENCE TO

Ashutosh Tandon, E: drashutoshtandon@gmail.com

\section{Introduction}

An incisional hernia is any abdominal wall gap with or without a bulge in the area of a postoperative scar, perceptible or palpable by clinical examination or imaging. ${ }^{1}$ Incisional hernias have been traditionally managed with open mesh repair with various techniques for mesh placement used, such as onlay, inlay and sublay (retrorectus) techniques. ${ }^{2}$ In the last 20 years, techniques for laparoscopic incisional hernia repair have evolved immensely. Laparoscopic incisional and ventral hernia repair (LIVHR) is now widely accepted for the repair of small- to medium-sized ventral hernia defects. While it is sometimes possible to repair large defects using this technique, these defects often require component separation and abdominal wall reconstruction. ${ }^{3}$ Laparoscopic repair has the advantages of a shorter hospital stay, less incidence of wound infection, less pain and adhesion formation. ${ }^{4}$ Common complications following laparoscopic mesh repair of incisional hernia are seroma formation, ileus, pain and wound infection. ${ }^{5}$ Intraperitoneal onlay placement of mesh is associated with poorer short- (ileus) and long-term outcomes (recurrence) and the risk of serious complications, such as bowel injury, are higher with the laparoscopic technique. ${ }^{4,6}$ The recurrence rate after laparoscopic incisional hernia repair has been reported to be between 0 to $9 \% .^{5}$

With advances in technology, various types of mesh and mesh fixation devices have become available. The choice of mesh in LIVHR is still open to debate, and the search for the 'ideal mesh' is still on. ${ }^{7}$ We performed a retrospective study at our centre, comparing two types of mesh commonly used, with a view to informing future surgical practice. 


\section{Materials and Methods}

A prospectively maintained database of all patients undergoing LIVHR at a district general hospital was reviewed for a 3-year period between January 2008 and December 2010. The study has been reported in the line with the STROBE Statement (Strengthening the reporting of observational studies in epidemiology). Data on baseline demographics, patient characteristics, intraoperative factors, and shortand long-term outcomes were collected.

\section{Preoperative assessment}

Patients were assessed with clinical examination regarding their functional status, weight, American Association of Anesthesiologists (ASA) grade, type and size of hernia defect. Those with clinically large hernias (defect size more than $10 \mathrm{~cm}$ ), multiple defects and/or a complex surgical history were scanned using computed tomography (CT) to assess the size of defect prior to surgery and to define anatomy.

\section{Operative approach}

Access to the abdominal cavity was achieved either by open insertion (Hasson's technique) or under direct vision using a $12 \mathrm{~mm}$ Endopath ${ }^{\circledR}$ XCEL $^{\circledR}$ (Ethicon Endo-Surgery Europe GmbH, Norderstedt, Germany) port. The abdominal wall defect was defined with blunt and/or sharp dissection and adhesiolysis. The hernia sac was not excised. An intraperitoneal onlay mesh with a minimum circumferential overlap of $5 \mathrm{~cm}$ around the defect, was placed and anchored circumferentially either with two rows of ProTack $^{\mathrm{TM}}$ (Covidien, New Haven, CT, USA) alone or transfacial sling sutures plus ProTack ${ }^{\mathrm{TM}}$. Port sites were closed with absorbable sutures. In the laparoscopy-assisted procedure, the sac was dissected via a mini-incision in the skin, the defect was repaired with interrupted non-absorbable suture and the mesh was fixed intraperitoneally using a laparoscopic approach. This technique was preferred by one of the surgeons for densely adherent hernia sacs that were deemed difficult to dissect laparoscopically.

\section{Mesh}

Two different types of meshes were used; the Parietex ${ }^{\mathrm{TM}}$ Composite mesh and the DynaMesh ${ }^{\circledR}$-IPOM (FEG Textiltechnik, Aachen, Germany). The Parietex ${ }^{\mathrm{TM}}$ composite mesh is made from a composite structure of monofilament polyester textile on one side and a hydrophilic absorbable collagen film on the other side. DynaMesh ${ }^{\circledR}-$ IPOM is a non-coated, $100 \%$ synthetic, two-component textile structure (polyvinylidene fluoride and polypropylene).

\section{Definitions}

A small hernia defect was defined as one with a maximum dimension of less than $4 \mathrm{~cm}$. A medium-sized defect was defined as $4-10 \mathrm{~cm}$ and a large defect was defined as being greater than $10 \mathrm{~cm} .{ }^{8}$ High BMI was defined as greater than $30 \mathrm{~kg} / \mathrm{m}^{2}$. Hernia recurrence was defined as radiological evidence of the same.

\section{Statistical analysis}

Statistical analysis was performed using SPSS $^{\circledR}$ (IBM) software version 20. The Mann-Whitney $\mathrm{U}$ test was used to compare quantitative variables with non-normal distribution. Patient demographics and operative characteristics were compared using the Fisher's exact test or the Chisquare test; $P$ values of less than 0.05 were considered as statistically significant. All the quantitative variables are represented in the results as percentages.

\section{Results}

A total of 88 patients underwent LIVHR between January 2008 and December 2010. Of these, 82 patients underwent laparoscopic incisional hernia repair, 5 patients had a laparoscopy-assisted procedure and 1 had conversion to open procedure; 39 patients were male and 49 were female. Median follow-up was 53.6 months (range, 40-61 months). Seventy-five patients $(85.2 \%)$ presented with a primary incisional hernia, ten $(11.4 \%)$ presented with a first recurrence and three (3.4\%) presented with a second recurrence from their previous hernia repairs. Sixty-six patients $(75 \%)$ had single defect either smaller than $4 \mathrm{~cm}$ or between $4 \mathrm{~cm}$ and $10 \mathrm{~cm}$; twenty-two patients $(25 \%)$ had multiple defects. Twenty-six patients with a median age of 61 years (range, 24-79 years) underwent LIVHR with a DynaMesh $^{\circledR}$-IPOM mesh, and Parietex ${ }^{\mathrm{TM}}$ Composite mesh was used in 62 patients with a median age of 57.5 years (range, 29-77 years). The male : female ratio was $1: 1.89$ in the DynaMesh ${ }^{\circledR}$-IPOM mesh group and $1: 1.07$ in the Parietex $^{\mathrm{TM}}$ Composite mesh group. BMI was high in 12 patients $(46 \%)$ in the DynaMesh ${ }^{\circledR}$-IPOM mesh group and in $35(56.45 \%)$ in the Parietex ${ }^{\mathrm{TM}}$ Composite mesh group. Most patients in both groups $\left(77 \%\right.$ in DynaMesh ${ }^{\circledR}$-IPOM mesh group and $74 \%$ in Pariete ${ }^{\mathrm{TM}}$ Composite mesh group) had a single defect. The characteristics of patients in the two groups were similar (Table 1). While the procedures were performed by four consultants in total, over the period of the study two of them exclusively used DynaMesh $^{\circledR}$-IPOM and two exclusively used Parietex ${ }^{\mathrm{TM}}$ Composite mesh.

There was no significant difference in operating time between patients with a high BMI $(n=46)$ and those with a lower BMI $(n=42)$. Although patients with a high BMI had a higher number of complications (23.9\% vs. $19.0 \%)$, this was not statistically significant. Similarly, although statistically not significant, a higher ASA grade was associated with a higher number of complications (ASA I 15\% vs. ASA II $21.8 \%$ vs. ASA III $30.8 \%$ ). There was no significant difference in the recurrence rate between single vs. multiple defect groups $(4.50 \%$ vs. $9 \%, P=0.423)$. In 45 patients, only ProTack $^{\mathrm{TM}}$ was used to fix the mesh, whereas in 43 patients both ProTack ${ }^{\mathrm{TM}}$ and transfascial suturing were used. Incidence of conversion to open operation was $1.1 \%$.

There was no mortality in the study. Overall morbidity was $20.5 \%$. Two patients $(2.2 \%)$ developed a chest infection in the postoperative period and one developed peritonitis in the immediate postoperative period, which 


\begin{tabular}{|c|c|c|c|}
\hline & DynaMesh®-IPOM & $\begin{array}{l}\text { Parietex }{ }^{\mathrm{TM}} \\
\text { Composite }\end{array}$ & $P$ value \\
\hline Total $(n)$ & 26 & 62 & \\
\hline $\begin{array}{l}\text { Median age } \\
\text { (years) (range) }\end{array}$ & $61(24-79)$ & $57.5(29-77)$ & $0.88^{a}$ \\
\hline Sex: & & & $0.244^{b}$ \\
\hline Male & 9 & 30 & \\
\hline Female & 17 & 32 & \\
\hline $\begin{array}{l}\text { Body mass } \\
\text { index }\left(\mathrm{kg} / \mathrm{m}^{2}\right) \text { : }\end{array}$ & & & $0.61^{b}$ \\
\hline$<30$ & 14 & 27 & \\
\hline $30-35$ & 7 & 23 & \\
\hline$>35$ & 5 & 12 & \\
\hline ASA grade: & & & $0.14^{c}$ \\
\hline 1 & 4 & 16 & \\
\hline 2 & 20 & 34 & \\
\hline 3 & 2 & 12 & \\
\hline Defect: & & & $0.79^{b}$ \\
\hline Single & 20 & 46 & \\
\hline Multiple & 6 & 16 & \\
\hline \multicolumn{4}{|c|}{ 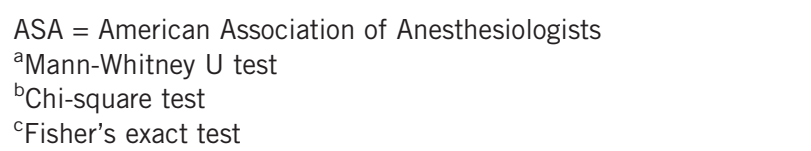 } \\
\hline
\end{tabular}

required a laparotomy, repair of enterotomy and removal of the mesh. One patient required a diagnostic laparoscopy on the first postoperative day for signs of peritonitis but no cause was found on laparoscopy for the same. Wound infection and sinus formation occurred in one patient with the Parietex ${ }^{\mathrm{TM}}$ Composite mesh $(1.1 \%)$.

The DynaMesh ${ }^{\circledR}$-IPOM group was associated with a significantly higher incidence of intestinal obstruction secondary to adhesions compared with the Parietex ${ }^{\mathrm{TM}}$ Composite group $(n=3,11.5 \%$, vs. $n=0,0 \% ; P=0.006)$. Of the three patients from the DynaMesh ${ }^{\circledR}$-IPOM group who developed intestinal obstruction (CT-proven), one required a laparotomy with removal of the mesh on 17th postoperative day. This patient had a large defect, for which two large DynaMesh ${ }^{\circledR}$-IPOM meshes had been used. At laparotomy, there were minimal interbowel loop adhesions and the small bowel loops were found to be extensively adherent to whole surface of the DynaMesh ${ }^{\circledR}$-IPOM mesh. The two remaining patients were managed conservatively. The breakdown of various other factors in these patients is shown in Table 2.

Mesh fixation in all three patients was with ProTack ${ }^{\mathrm{TM}}$. Eight patients $(12.9 \%)$ in the Parietex ${ }^{\mathrm{TM}}$ Composite mesh group developed a recurrence (Table 3) in comparison with one patient $(3.8 \%)$ in the DynaMesh ${ }^{\circledR}$-IPOM mesh group $(P=0.201)$. There were no patients with seroma or hematoma formation in the DynaMesh ${ }^{\circledR}$-IPOM mesh group, whereas four patients $(6.4 \%)$ in the Parietex ${ }^{\mathrm{TM}}$ Composite mesh group $(P=0.185)$ developed a seroma and/or haematoma. Of these, two patients developed a haematoma in the early postoperative period, which was assessed clinically and with ultrasound, and two patients were diagnosed with a seroma on ultrasound scan 6 weeks postoperatively, which settled spontaneously in follow-up and required no further intervention.

\section{Discussion}

While laparoscopic repair of incisional hernia has been established as a well-accepted technique with benefits over the open procedure, there are concerns over a higher incidence of intraperitoneal onlay mesh (IPOM) related complications and higher rates of visceral injuries. Since the introduction of laparoscopic incisional hernia repair, various types of mesh have been introduced. However, the search for the 'ideal' mesh, which causes the fewest adhesions, seroma and infection continues. The aim of this study was to add to the current evidence base and to help inform future practice.

Our findings suggest that there is a higher incidence of mesh-related complications associated with use of the DynaMesh $^{\circledR}$-IPOM compared with Parietex ${ }^{\mathrm{TM}}$ Composite mesh in LIVHR. In a small series of patients, DynaMesh ${ }^{\circledR}$ IPOM was associated with a high incidence of bowel obstruction caused by adhesion of the whole surface of the mesh to the bowel, with histologically proven severe foreign body reaction in the bowel. ${ }^{9}$ Various experimental models and studies suggest decreased adhesion formation with the use of the Parietex ${ }^{\mathrm{TM}}$ Composite mesh, ${ }^{10-14}$ with most suggesting that coated meshes perform better, with less adhesion formation. The guidelines for laparoscopic treatment of ventral and incisional abdominal wall hernias suggest that more research is needed to understand the mesh requirement for individual groups of patients who react differently to different types of mesh. ${ }^{15}$

Seroma formation post-LIVHR is also common, with various studies having reported the occurrence of seroma in the range of $4-8 \%$ following LIVHR. ${ }^{15}$ A slightly higher rate of seroma/haematoma formation was noted in the Parietex ${ }^{\mathrm{TM}}$ Composite group in our study. Coated meshes, which are commonly used in intraperitoneal mesh repairs, are typically associated with seroma formation because of the resulting impaired drainage of fluid due to the barrier coating. ${ }^{9}$ There may be other contributing factors, such as the number and size of the defects, difficulty of dissection, mesh fixation technique and operation time. ${ }^{15}$

The optimal mesh type for LIVHR has yet to be established. Previous randomised trials in the field of incisional hernia have tended to focus on either the approach (laparoscopic vs. open) or method of fixation (tacker, suture, glue, etc.). There has been only one randomised controlled trial comparing mesh type (titanium-coated lightweight mesh vs. standard composite mesh), which showed no differences in recurrence rates but lower incidence of pain- 
Table 2 Breakdown of characteristics of patients who had laparoscopic incisional and ventral hernia repair and complications

\begin{tabular}{|c|c|c|c|c|c|c|c|c|c|c|c|}
\hline \multirow{2}{*}{$\begin{array}{l}\text { Age } \\
\text { (years) }\end{array}$} & \multirow{2}{*}{ Sex } & \multirow{2}{*}{$\begin{array}{l}\text { BMI } \\
\left(\mathrm{kg} / \mathrm{m}^{2}\right)\end{array}$} & \multirow{2}{*}{$\begin{array}{l}\text { ASA } \\
\text { grade }\end{array}$} & \multirow[t]{2}{*}{ Indication } & \multirow[t]{2}{*}{ Defect } & \multicolumn{3}{|c|}{ Mesh } & \multirow{2}{*}{$\begin{array}{l}\text { Duration } \\
\text { of procedure } \\
\text { (minutes) }\end{array}$} & \multirow{2}{*}{$\begin{array}{l}\text { Complication } \\
\text { (management) }\end{array}$} & \multirow{2}{*}{$\begin{array}{l}\text { Grade of } \\
\text { complications }^{a}\end{array}$} \\
\hline & & & & & & Type & $\begin{array}{l}\text { Size } \\
(\mathrm{cm})\end{array}$ & $\begin{array}{l}\text { Fixation } \\
\text { technique }\end{array}$ & & & \\
\hline 37 & $\mathrm{M}$ & 36 & 2 & $\begin{array}{l}\text { First } \\
\text { recurrence }\end{array}$ & Single & $\begin{array}{l}\text { DynaMesh®- } \\
\text { IPOM }\end{array}$ & $20 \times 20$ & ProTack $^{\text {TM }}$ & 110 & $\begin{array}{l}\text { Small bowel } \\
\text { obstruction } \\
\text { (conservative) }\end{array}$ & I \\
\hline 31 & $\mathrm{~F}$ & 29.5 & 1 & Primary & Single & $\begin{array}{l}\text { DynaMesh®- } \\
\text { IPOM }\end{array}$ & $10 \times 15$ & ProTack $^{\mathrm{TM}}$ & 63 & $\begin{array}{l}\text { Small bowel } \\
\text { obstruction } \\
\text { (conservative) }\end{array}$ & I \\
\hline 55 & $M$ & 36 & 2 & Primary & Single & $\begin{array}{l}\text { DynaMesh®- } \\
\text { IPOM }\end{array}$ & $\begin{array}{l}15 \times 20 \\
20 \times 30\end{array}$ & ProTack $^{\mathrm{TM}}$ & 130 & $\begin{array}{l}\text { Adhesive } \\
\text { obstruction } \\
\text { (laparotomy) }\end{array}$ & IIIB \\
\hline 75 & $M$ & 22 & 2 & Primary & Single & $\begin{array}{l}\text { Parietex }{ }^{\mathrm{TM}} \\
\text { Composite }\end{array}$ & $20 \times 15$ & $\begin{array}{l}\text { ProTack }^{\mathrm{TM}} \text { and } \\
\text { transfacial } \\
\text { sutures }\end{array}$ & 120 & Seroma & I \\
\hline 34 & M & 25 & 1 & Primary & Single & $\begin{array}{l}\text { Parietex }{ }^{\mathrm{TM}} \\
\text { Composite }\end{array}$ & $20 \times 15$ & $\begin{array}{l}\text { ProTack }^{\mathrm{TM}} \text { and } \\
\text { transfacial } \\
\text { sutures }\end{array}$ & 60 & Hematoma & I \\
\hline 70 & $M$ & 42 & 3 & $\begin{array}{l}\text { First } \\
\text { recurrence }\end{array}$ & Single & $\begin{array}{l}\text { Parietex }{ }^{\mathrm{TM}} \\
\text { Composite }\end{array}$ & $30 \times 20$ & $\begin{array}{l}\text { ProTack }^{\mathrm{TM}} \text { and } \\
\text { transfacial } \\
\text { sutures }\end{array}$ & 120 & Hematoma & I \\
\hline 52 & $\mathrm{M}$ & 31 & 2 & Primary & Single & $\begin{array}{l}\text { Parietex }{ }^{\mathrm{TM}} \\
\text { Composite }\end{array}$ & $20 \times 15$ & $\begin{array}{l}\text { ProTack }^{\mathrm{TM}} \text { and } \\
\text { transfacial } \\
\text { sutures }\end{array}$ & 150 & Seroma & I \\
\hline
\end{tabular}

related complications in the titanium-coated mesh group. ${ }^{16}$ There are only a few comparative studies of mesh types in LIVHR, with only Chelala et al., ${ }^{17}$ reporting long-term follow-up of 85 patients undergoing LIVHR from a cohort of 733 who had undergone repeat laparoscopy for various reasons. Serosal adhesions were found in only $10 \%$ of cases with no mesh-related complications.

In our study, a higher (although not statistically significant) recurrence rate of $12.9 \%$ was noted in the Parietex ${ }^{\mathrm{TM}}$ Composite mesh group as compared to the DynaMesh ${ }^{\circledR}$ IPOM mesh group. Comparable single-institution case series and one multicentre randomised study reported recurrence rates as low as $0-2.5 \%,{ }^{18-22}$ whereas prospective national registries have suggested much higher recurrence rates of $15.5 \%$ at a median of 21 months follow up. ${ }^{6}$ Other contributing factors for recurrence of hernia include the number and size of the defects, difficulty of dissection, mesh fixation technique and operation. ${ }^{18-22}$ Our study showed no significant relation between mesh fixation with transfascial sutures and non-absorbable tackers and recurrence of hernia, which is consistent with the existing literature. $^{23,24}$ There has been a recent focus on the use of fibrin glue for mesh fixation, particularly in areas such as the subcostal margins and close to the xiphisternum and pelvis. Other studies have emphasised that mesh fixation using fibrin glue in patients with LIVHR is associated with less postoperative pain. ${ }^{25,26}$ The association between postoperative pain and fixation devices needs further research.

We accept the limitations of our study, which was performed retrospectively and includes a relatively small number of patients. However, further to this study, the practice in our hospital has been changed and we have now discontinued using DynaMesh ${ }^{\circledR}$-IPOM in LIVHR. We appreciate that there is a need to undertake well-designed, multicentre, randomised controlled trials to investigate the various types of meshes used in LIVHR, with a view to informing future practice.

\section{Conclusions}

LIVHR is a safe and feasible technique. In our study, Dynamesh ${ }^{\circledR}$-IPOM has been shown to be associated with a significantly higher incidence of adhesion-related bowel obstruction, albeit with a lower incidence of recurrence, seroma and haematoma formation as compared with Parietex $^{\mathrm{TM}}$ Composite mesh. However, there is a need for further well-designed, multicentre randomised controlled studies to investigate the use of these meshes. 


\section{Table 3 Breakdown of characteristics of patients who had LIVHR repair and recurrence of hernia as a complication}

\begin{tabular}{|c|c|c|c|c|c|c|c|c|c|c|}
\hline \multirow{2}{*}{$\begin{array}{l}\text { Age } \\
\text { (years) }\end{array}$} & \multirow[t]{2}{*}{ Sex } & \multirow{2}{*}{$\begin{array}{l}\text { BMI } \\
\left(\mathrm{kg} / \mathrm{m}^{2}\right)\end{array}$} & \multirow{2}{*}{$\begin{array}{l}\text { ASA } \\
\text { grade }\end{array}$} & \multirow[t]{2}{*}{ Indication } & \multirow{2}{*}{$\begin{array}{l}\text { Type of } \\
\text { defect }\end{array}$} & \multicolumn{3}{|c|}{ Mesh } & \multirow{2}{*}{$\begin{array}{l}\text { Duration of } \\
\text { procedure } \\
\text { (minutes) }\end{array}$} & \multirow{2}{*}{$\begin{array}{l}\text { Duration of } \\
\text { recurrence } \\
\text { from hernia repair } \\
\text { (days) }\end{array}$} \\
\hline & & & & & & Type & $\begin{array}{l}\text { Size } \\
(\mathrm{cm})\end{array}$ & $\begin{array}{l}\text { Fixation } \\
\text { technique }\end{array}$ & & \\
\hline 37 & M & 41 & 2 & $\begin{array}{l}\text { Second } \\
\text { recurrence }\end{array}$ & Multiple & $\begin{array}{l}\text { Parietex }{ }^{\mathrm{TM}} \\
\text { Composite }\end{array}$ & $\begin{array}{l}25 \times 20 \\
20 \times 15\end{array}$ & ProTack ${ }^{\mathrm{TM}}$ & 75 & $>30$ days \\
\hline 74 & $\mathrm{~F}$ & 33 & 3 & Primary & Single & $\begin{array}{l}\text { Parietex }{ }^{\mathrm{TM}} \\
\text { Composite }\end{array}$ & $25 \times 20$ & ProTack ${ }^{\mathrm{TM}}$ & 125 & $>30$ days \\
\hline 37 & M & 33 & 1 & Primary & Single & $\begin{array}{l}\text { Parietex }{ }^{\mathrm{TM}} \\
\text { Composite }\end{array}$ & $25 \times 20$ & ProTack ${ }^{\mathrm{TM}}$ & 110 & $>30$ days \\
\hline 62 & $F$ & 35 & 3 & Primary & Single & $\begin{array}{l}\text { Parietex } \\
\text { Composite }\end{array}$ & $15 \times 10$ & $\begin{array}{l}\text { ProTack }^{\mathrm{TM}} \\
\text { and transfacial } \\
\text { sutures }\end{array}$ & 75 & $>30$ days \\
\hline 69 & $\mathrm{M}$ & 33 & 2 & Primary & Multiple & $\begin{array}{l}\text { Parietex }{ }^{\mathrm{TM}} \\
\text { Composite }\end{array}$ & $15 \times 10$ & $\begin{array}{l}\text { ProTack }^{\mathrm{TM}} \\
\text { and transfacial } \\
\text { sutures }\end{array}$ & 90 & $>30$ days \\
\hline 65 & M & 32 & 2 & $\begin{array}{l}\text { First } \\
\text { recurrence }\end{array}$ & Single & $\begin{array}{l}\text { Parietex }{ }^{\mathrm{TM}} \\
\text { Composite }\end{array}$ & $20 \times 15$ & ProTack $^{\mathrm{TM}}$ & 100 & $>30$ days \\
\hline 42 & $F$ & 38 & 2 & Primary & Single & $\begin{array}{l}\text { Parietex }{ }^{\mathrm{TM}} \\
\text { Composite }\end{array}$ & $25 \times 20$ & $\begin{array}{l}\text { ProTack }^{\mathrm{TM}} \\
\text { and transfacial } \\
\text { sutures }\end{array}$ & 115 & $>30$ days \\
\hline 67 & M & 33 & 2 & Primary & Multiple & $\begin{array}{l}\text { Parietex }{ }^{\mathrm{TM}} \\
\text { Composite }\end{array}$ & $25 \times 20$ & $\begin{array}{l}\text { ProTack }^{\mathrm{TM}} \\
\text { and transfacial } \\
\text { sutures }\end{array}$ & 120 & $>30$ days \\
\hline 79 & $\mathrm{~F}$ & 28 & 2 & Primary & Single & $\begin{array}{l}\text { DynaMesh®- } \\
\text { IPOM }\end{array}$ & $12 \times 12$ & ProTack ${ }^{\mathrm{TM}}$ & 205 & $<30$ days \\
\hline
\end{tabular}

\section{Acknowledgement}

NJS declares that he has received honoria from Medtronic for lecturing on hernia surgery.

All other authors confirm that they have no conflict of interest to declare.

\section{References}

1. Korenkov M, Paul A, Sauerland S et al. Classification and surgical treatment of incisional hernia. Results of an experts' meeting. Langenbeck's Arch Surg 2001; 386(1): 65-73.

2. Millikan KW. Incisional hernia repair. Surg Clin North Am 2003; 83(5): $1,223-1,234$.

3. de Vries Reilingh TS, van Goor H, Charbon JA et al. Repair of giant midline abdominal wall hernias: 'components separation technique' versus prosthetic repair : interim analysis of a randomized controlled trial. World J Surg 2007; 31(4): 756-763.

4. Zhang $\mathrm{Y}$, Zhou H, Chai $\mathrm{Y}$ et al. Laparoscopic versus open incisional and ventral hernia repair: a systematic review and meta-analysis. World J Surg 2014; 38(9): 2233-2240.

5. Cassar K, Munro A. Surgical treatment of incisional hernia. Br J Surg 2002 89(5): 534-545.

6. Helgstrand $\mathrm{F}$, Rosenberg $\mathrm{J}$, Kehlet $\mathrm{H}$ et al. Nationwide prospective study of outcomes after elective incisional hernia repair. J Am Coll Surg 2013; 216(2) 217-228.

7. Bringman S, Conze J, Cuccurullo $\mathrm{D}$ et al. Hernia repair: the search for ideal meshes. Hernia 2010; 14(1): 81-87.
8. Muysoms FE, Miserez $\mathrm{M}$, Berrevoet $\mathrm{F}$ et al. Classification of primary and incisional abdominal wall hernias. Hernia 2009; 13(4): 407-414.

9. Fortelny RH, Petter-Puchner AH, Glaser KS et al. Adverse effects of polyvinylidene fluoride-coated polypropylene mesh used for laparoscopic intraperitoneal onlay repair of incisional hernia. Br J Surg 2010; 97(7): $1,140-1,145$

10. Burger JW, Halm JA, Wijsmuller AR et al. Evaluation of new prosthetic meshes for ventral hernia repair. Surg Endosc 2006; 20(8): 1,320-1,325.

11. McGinty JJ, Hogle NJ, McCarthy $\mathrm{H}$ et al. A comparative study of adhesion formation and abdominal wall ingrowth after laparoscopic ventral hernia repair in a porcine model using multiple types of mesh. Surg Endosc 2005; 19(6): 786-790

12. Kayaoglu HA, Ozkan N, Hazinedaroglu SM et al. Comparison of adhesive properties of five different prosthetic materials used in hernioplasty. $J$ Invest Surg 2005; 18(2): 89-95

13. Schreinemacher MH, van Barneveld KW, Dikmans RE et al. Coated meshes for hernia repair provide comparable intraperitoneal adhesion prevention. Surg Endosc 2013; 27(11): 4,202-4,209.

14. Deeken CR, Faucher KM, Matthews BD. A review of the composition, characteristics, and effectiveness of barrier mesh prostheses utilized for laparoscopic ventral hernia repair. Surg Endosc 2012; 26(2): 566-575

15. Bittner R, Bingener-Casey J, Dietz U et al. Guidelines for laparoscopic treatment of ventral and incisional abdominal wall hernias (International Endohernia Society [IEHS]) Part 2. Surg Endosc 2014; 28(2): 353-379.

16. Moreno-Egea A, Carrillo-Alcaraz A, Soria-Aledo V. Randomized clinical trial of laparoscopic hernia repair comparing titanium-coated lightweight mesh and medium-weight composite mesh. Surg Endosc 2013; 27(1): 231-239.

17. Chelala E, Debardemaeker $Y$, Elias $B$ et al. Eighty-five redo surgeries after 733 laparoscopic treatments for ventral and incisional hernia: adhesion and recurrence analysis. Hernia 2010; 14(2): 123-129. 
18. Olmi S, Erba L, Magnone S et al. [Prospective study of laparoscopic treatment of incisional hernia by means of the use of composite mesh: indications, complications, mesh fixation materials and results]. Chir Ital 2005; 57(6): 709-716.

19. Nardi MJ, Millo P, Brachet Contul R et al. Laparoscopic incisional and ventral hernia repair (LIVHR) with PARIETEX Composite mesh. Minim Invas Ther Allied Technol 2012; 21(3): 173-180.

20. Balique JG, Benchetrit S, Bouillot JL et al. Intraperitoneal treatment of incisional and umbilical hernias using an innovative composite mesh: four-year results of a prospective multicenter clinical trial. Hernia 2005; 9(1): 68-74.

21. Rosen MJ. Polyester-based mesh for ventral hernia repair: is it safe? Am J Surg 2009; 197(3): 353-359.

22. Moreno-Egea A, Liron R, Girela $\mathrm{E}$ et al. Laparoscopic repair of ventral and incisional hernias using a new composite mesh (Parietex): initial experience. Surg Laparosc Endosc Percutan Tech 2001; 11(2): 103-106.
23. Brill JB, Turner PL. Long-term outcomes with transfascial sutures versus tacks in laparoscopic ventral hernia repair: a review. Am Surg 2011; 77(4): 458-465.

24. Wassenaar E, Schoenmaeckers E, Raymakers J et al. Mesh-fixation method and pain and quality of life after laparoscopic ventral or incisional hernia repair: a randomized trial of three fixation techniques. Surg Endosc 2010; 24(6): $1,296-1,302$.

25. Olmi S, Scaini A, Erba $L$ et al. Use of fibrin glue (Tissucol) in laparoscopic repair of abdominal wall defects: preliminary experience. Surg Endosc 2007; 21(3): 409-413.

26. Eriksen JR, Bech JI, Linnemann D, Rosenberg J. Laparoscopic intraperitoneal mesh fixation with fibrin sealant (Tisseel) vs. titanium tacks: a randomised controlled experimental study in pigs. Hernia 2008; 12(5): 483-491. 